\title{
The Fatal Alcoholic Ketoacidosis as a Dilemma in the Differential Diagnosis in Unexpected Deaths
}

\author{
Komarekova I*, Novomesky F and Straka L
}

Department of Forensic Medicine and Medicolegal Expertises, Jessenius Medical Faculty in Martin, Commenius University in Bratislava

${ }^{*}$ Corresponding author: Komarekova I. MD, Department of Forensic Medicine and Medicolegal Expertises, Kollarova 2, 03601 Martin, Slovakia, E-mail: ivakomarekova@gmail.com

Citation: Komarekova I, Novomesky F, Straka L (2014) The Fatal Alcoholic Ketoacidosis as a Dilemma in the Differential Diagnosis in Unexpected Deaths. J Forensic Sci Criminol 2(1): 101. doi: 10.15744/23489804.1.401

\section{Received Date: November 26, 2013 Accepted Date: February 11, 2014 Published Date: February 14, 2014}

\section{Case report}

48-years old man was found dead at home, lying in his bed. There was a bucket with liquid vomited remnants with no addition of fresh or digested blood found near the bed and an empty bottle of alkaline mineral water often used to attenuate the gastric pain. Up to the information from the man's relative, he was a chronic alcohol consumer, being last seen alive the day before in the pub, drinking small amount of beer. His personal anamnesis was negative for the previous injuries or any pathological entity which could have potential fatal outcome. External observation of the body did not uncover any signs of mechanical violence on the body. The only pathological findings at the autopsy were: very mild generalised atherosclerosis without stenosis of blood vessels, configuration of the heart with the weight of $400 \mathrm{~g}$ was physiological, with no signs of chronic venostatic changes on the internal organs. The microscopical examination did not find any ischemic changes of myocardial muscle. The deceased had diffuse alcoholic steatosis of the liver. The brain was mildly swollen (weight 1300 g) without conformation of conuses and cross section revealed no pathological or traumatic lessions. Results of alcoholimetric analysis were absolutely negative for the presence of ethanol in blood or urine. Toxicological analysis did not notice any psychoactive substances or medicaments, the only finding was positive acetone in blood, level of which was $435 \mathrm{mg} / \mathrm{l}$ and highly increased betahydroxybutyric acid (BHBA) blood level of $272 \mathrm{mg} / \mathrm{l}$, while acetonuria was $962 \mathrm{mg} / \mathrm{l}$. Biochemical analysis showed a reduced blood $\mathrm{pH}=7.21$ which is not reliable as it could be the only a postmortem artefact. Sample of vitreous humour showed glucose levels of $3.1 \mathrm{mmol} / \mathrm{l}$.

\section{Discussion}

Summarising the morphological findings from the autopsy and histology together with the results of additional laboratory tests performed in upper mentioned case, we obtain the three basic biochemical entities which being combined consequently, result in unique metabolic condition: ketosis (increased acetone and BHBA in blood and urine) and a few indirect indicators of probable acidosis and hypoglycaemia prior to death. Blood glucose level measurement is of no use in forensic pathology due to fluctuating glucose levels in postmortal period when the glycolysis still continues, so some authors suggest to establish the blood glucose level prior to death by the sum of the glucose and lactate level in the vitreous humour or cerebrospinal fluid [1]. Data from post-mortem blood acetone, BHBA concentrations and vitreous humour glucose concentrations have been collected to determine the markers required to identify and distinguish between the most probable metabolic disturbances leading potentially to deaths of young individuals in the similar cases - AKA, diabetic ketoacidosis (DKA) and hyperosmolar hyperglycaemic state (HHS) [2-4]. Vitreous humour glucose concentrations above $6.9 \mathrm{mmol} / \mathrm{l}$ are considered high and indicative of hyperglycaemia prior to death and so important in distinguishing between DKA, HHS or ketoacidosis from other causes [2]. Blood BHBA concentrations higher than $250 \mathrm{mg} / \mathrm{l}$ are considered significant, so it is supposed to be the preferred marker of ketoacidosis [2]. Cases with significant BHBA detected also had the acetone present, demonstrating that the acetone can be used as an initial marker to identify ketoacidosis, thus the acetone can be used to indicate whether BHBA detection is necessary [4]. Diagnosis of diabetic ketoacidosis can be excluded because of the absence of increased glucose levels in the vitreous humour which tightly corresponds to blood glucose levels. The most common test measuring the Hbcla can easily indicate the blood glucose levels even for the previous two or three months which could be very helpful and reliable in the differential diagnostic process [5]. Also estimating the C-reactive protein, interleukin-6 and interleukin-10 proved that these parameters use to be elevated in the cases of diabetic ketoacidosis [6]. Exclusion of DKA in our case was supported by the consultation with the deceased's general practitioner who confirmed that diabetes has never been diagnosed in the deceased man before and testing for the previously mentioned inflammatory markers was negative. No previous head traumas and no loci epileptogenes in the brain as well as no previous clinical signs of epilepsy help us to exclude this diagnosis. While having an episode of hard and continuous drinking without appropriate intake of food, we consider alcoholic ketoacidosis (AKA) as the most probable cause of 
death. Recent clinical and even forensic studies provide an increasing amount of evidence that rather than being benign, the alcoholic ketoacidosis and related metabolic disturbances may be a cause of mortality in patients with chronic alcohol dependence $[7,8]$. Denmark noted elevated BHBA levels in a few unexplained deaths and hypothesised that AKA may have caused fatal hypoglycaemia which could have lead to death [9]. Thomsen et al theorised that the acidosis itself causes metabolic disruptions of vital functions leading to death [10]. The authors subsequently reported ketoalcoholic deaths in 7\% of sudden deaths in alcoholic patients in a prospective series [11].

A reduced blood $\mathrm{pH}$, resulting from the production of ketone bodies as a result of chronic alcoholism (or diabetes) may play the main role in many fatalities, in which any other cause of death can be excluded. However, in cases of abdominal pains and few vomiting periods, blood $\mathrm{pH}$ can vary due to interference with partial metabolic alkalosis after periods of excessive vomiting and respiratory alkalosis caused by severe abdominal pain and consequent Kussmaul breathing pattern. Analytical evidence should be expressly used as a dominant support of a final diagnosis, or it itself may provide a possible cause of death in the absence of other pathologically significant postmortal findings. Therefore AKA must be taken into account in the differential diagnosis of any suddenly deceased chronic alcoholic patient with metabolic acidosis and ketosis. The fundamental reason of AKA development in chronic alcohol drinking persons is that they undergo a period of binge drinking, associated with a negligible intake of solid food. After the characteristic development of abdominal pain and severe vomiting - due to pancreatitis, gastritis, or acute hepatitis - the person usually stops drinking. If the drinker dies subsequently, the presentation of ethanol in blood is frequently undetectable in the sample taken during the autopsy [12]. The combination of AKA and hypoglycaemic state in non-diabetic persons has not been described in the literature as a clinical entity, but still it is potentially serious consequence of chronic alcohol intake. Although its medical treatment is simple and effective, this entity may have a fatal outcome and therefore it must be deliberated in suddenly deceased chronic alcohol consumers. On the other hand, the hyperglycemia and glycosuria that accompany severe ketoacidosis in diabetes are absent, as it was confirmed by vitreous humour glucose level measurment and urine analysis in presented case.

\section{References}

1. Palmiere C, Mangin P (2012) Postmortem chemistry update part I. Int J Legal Med 126: 187-98.

2. Hockenhull J, Dhillo W, Andrews R, Paterson S (2012) Investigation of markers to indicate and distinguish death due to alcoholic ketoacidosis, diabetic ketoacidosis and hyperosmolar hyperglycemic state using post-mortem samples. Forensic Sci Int 214: 142-7.

3. Felby S, Nielsen E, Thomsen JL (2008) The postmortem distribution of ketone bodies between blood, vitreous humor, spinal fluid, and urine. Forensic Sci Med Pathol 4: 100-7.

4. Elliott S, Smith C, Cassidy D (2010) The post-mortem relationship between beta-hydroxybutyrate (BHB), acetone and ethanol in ketoacidosis. Forensic Sci Int 198: 53-7.

5. Jovanovic L, Peterson CM (1981) The clinical utility of glycosylated hemoglobin. Am J Med 70: 331-8.

6. Palmiere C, Bardy D, Mangin P, Werner D (2013) Postmortem diagnosis of unsuspected diabetes mellitus. Forensic Sci Int 226: 160-7.

7. McGuire LC, Cruickshank AM, Munro PT (2006) Alcoholic ketoacidosis. Emerg Med J 23: 417-20.

8. Yanagawa Y, Hirano Y, Takemoto M, Takei T, Itoet T, et al. (2012) Characteristics of severe alcoholic ketoacidosis with a reversible visual disturbance. J Clinic Toxicol 2011: S7-001.

9. Denmark LN (1993) The investigation of beta-hydroxybutyrate as a marker for sudden death due to hypoglycaemia in alcoholics. Forensic Sci Int 62: 22532.

10. Thomsen JL, Simonsen KW, Felby S, Frohlich B (1997) A prospective toxicology analysis in alcoholics. Forensic Sci Int 90: 33-40.

11. Thomsen JL, Felby S, Theilade P, Nielsen E (1995) Alcoholic ketoacidosis as a cause of death in forensic cases. Forensic Sci Int 75: 163-71.

12. Umpierrez GE, DiGirolamo M, Tuvlin JA, Isaacs SD, Bhoola SM, et al. (2000) Differences in metabolic and hormonal milieu in diabetic- and alcoholinduced ketoacidosis. J Crit Care 15: 52-9.

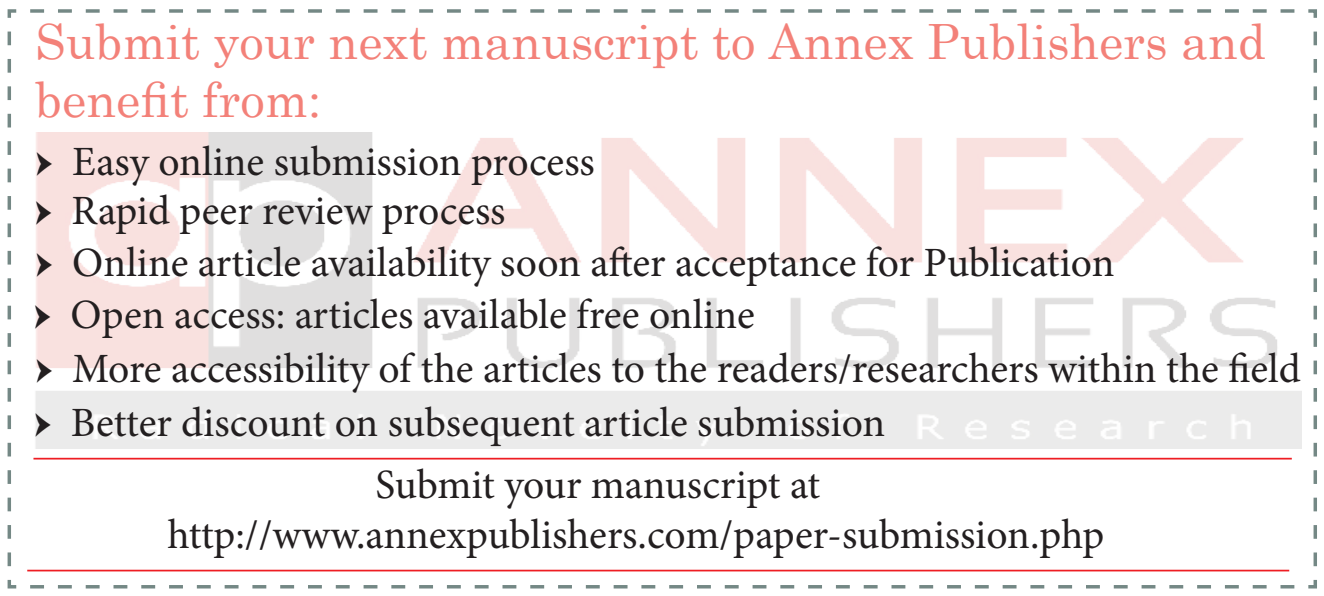

